Abstracta Iranicacta Iranica

Revue bibliographique pour le domaine irano-aryen

Volume 37-38-39 | 2018

Comptes rendus des publications de 2014-2016

\title{
Bruno Jacobs. „Zur bildlichen Repräsentation iranischer Eliten im achämenidenzeitlichen Kleinasien“
}

\section{Astrid Nunn}

\author{
(2) OpenEdition \\ Journals \\ Édition électronique \\ URL : http://journals.openedition.org/abstractairanica/44182 \\ DOI : 10.4000/abstractairanica.44182 \\ ISBN : 1961-960X \\ ISSN : 1961-960X \\ Éditeur : \\ CNRS (UMR 7528 Mondes iraniens et indiens), Éditions de l'IFRI
}

\section{Référence électronique}

Astrid Nunn, « Bruno Jacobs. „Zur bildlichen Repräsentation iranischer Eliten im

achämenidenzeitlichen Kleinasien" », Abstracta Iranica [En ligne], Volume 37-38-39 | 2018, document

27, mis en ligne le 30 décembre 2018, consulté le 02 octobre 2020. URL : http://

journals.openedition.org/abstractairanica/44182 ; DOI : https://doi.org/10.4000/abstractairanica 44182

Ce document a été généré automatiquement le 2 octobre 2020.

Tous droits réservés 


\title{
Bruno Jacobs. „Zur bildlichen Repräsentation iranischer Eliten im achämenidenzeitlichen Kleinasien“
}

\author{
Astrid Nunn
}

\section{RÉFÉRENCE}

Bruno Jacobs. „Zur bildlichen Repräsentation iranischer Eliten im achämenidenzeitlichen Kleinasien“" in S. Farridnejad, R. Gyselen, A. Joisten-Pruschke (eds.). Faszination Iran. Beiträge zur Religion, Geschichte und Kunst des Alten Iran. Gedenkschrift für Klaus Schippmann. Wiesbaden, 2015, p. 101-128.

1 Outre le satrape avec ses fonctionnaires et ses militaires, nombreux furent les Perses, marchands, scribes et prêtres qui arrivèrent en Anatolie après la conquête par Cyrus le Grand. L'A. glane les dates personnelles que l'on peut avoir sur ces individus qui certainement formèrent une élite. Les sources écrites proviennent e.a. de Sardes et Daskyleion. L'A. se pose ici la question de savoir comment cette élite se représentait en image, sachant que cette autoreprésentation aurait été impossible dans son pays d'origine puisque les représentations individuelles étaient limitées au Roi. Le processus d'acculturation dans la manière de se faire représenter est le sujet de nombreuses études. L'A. étudie plus particulièrement le développement d'une iconographie discrète, soit parce qu'elle se trouve sur des petits objets (bulles de Daskyleion), soit parce que les personnes ne portent aucune caractéristique perse (plusieurs stèles funéraires). Seule l'iconographie de reliefs ou de peintures tels ceux de Meydancikkale, Karaburun ou Tatarlı permettent d'identifier des Perses, à condition que les porteurs $\mathrm{du}$ vêtement perse soient bien perses. Etre ainsi reconnaissable est aussi l'expression d'une identité propre et de la volonté de se singulariser dans un milieu étranger. 


\section{AUTEURS}

\section{ASTRID NUNN}

Université de Munich 